\title{
Towords Education 2030: Construction and Implementation of Lifelong Inclusive Education Curriculum System
}

\author{
Feng Xia, Yuyun Wen*, Xichun Yan \\ Shanghai Changning Special Education Guidance Center, Shanghai, China \\ Email address: \\ 13701910328@163.com (Feng Xia),121345265@qq.com (Yuyun Wen),648244604@qq.com (Xichun Yan) \\ ${ }^{*}$ Corresponding author
}

To cite this article:

Feng Xia, Yuyun Wen, Xichun Yan. Towords Education 2030: Construction and Implementation of Lifelong Inclusive Education Curriculum System. International Journal of Elementary Education. Vol. 9, No. 2, 2020, pp. 30-36. doi: 10.11648/j.ijeedu.20200902.12

Received: June 5, 2020; Accepted: June 29, 2020; Published: July 6, 2020

\begin{abstract}
Responding to the general objective of UNESCO Education 2030 Framework for Action, and promoting the development of its spirit" Ensure inclusive and equitable quality education and promote lifelong learning opportunities for all", Shanghai Changning Special Education Guidance Center began to explore the lifelong inclusive education curriculum system. Based on the concepts of "Lifelong, Inclusive, Support, and Talent" and characterized by whole-process, whole people, inclusiveness, growth, and selectivity, the curriculum take the center project as the starting point, it integrates resources such as special education schools, teaching and research institutions, hospitals, and rehabilitation institutions. From direct services to indirect services, serving two dimensions to cut through, forming a four-dimensional "LIST" course for the SENs, parents, teachers, and schoolmasters. The lifelong inclusive education curriculum system is inspired by the postmodern curriculum theory, and break through the traditional special education curriculum paradigm. The lifelong inclusive education curriculum system has realized the enlargement of learning segment, the extension of handicap types, and the expansion of service objects. The construction and implementation of the curriculum system has changed the overall appearance of regional special education. The action of Shanghai Changning Special Education Guidance Center provided a sample of regional lifelong inclusive education curriculum system.
\end{abstract}

Keywords: Education 2030 Action Framework, Lifelong Inclusive Education Curriculum, Curriculum System Construction and Implementation

\section{Introduction}

In 2015, the Education 2030 Framework for Action issued by UNESCO set out the general goal of ensuring inclusive and equitable quality education so that everyone has access to lifelong learning opportunities [1]. In response to this general goal, the Fourth Plenary Session of the 19th Central Committee proposed to build an education system that serves the people's lifelong learning for all [2]. Special education is for people with disabilities and other people with special education needs. The development of special education is related to the realization of educational equity and the protection of the rights of disabled persons to education [3]. In addition, the level of special education development can largely reflect the comprehensive level of the political, economic, cultural and national qualities of a country or region, and has gradually become an important indicator of the progress of social civilization [4]. Special education is an important part of the national education system [5]. Constructing a life-long learning system that serves exceptional people has great significance to improving the education system of lifelong learning for all. It means that special education should provide students with special education needs (abbreviated as SENs) of all ages with the opportunity to obtain lifelong knowledge, skills and values, that is, to obtain lifelong inclusive education opportunities.

In 2016, the Ministry of Education of China officially released the compulsory education curriculum standards for three types of special education schools: blind, deaf, and mentally handicapped [6]. It is the first time in China that a whole set of systematic learning standards has been formulated for students with disabilities [7]. At present, China has formed a three-level curriculum management system of state, local and school, and has established a 
relatively mature compulsory education curriculum system of three kinds of special education schools for the blind, the deaf and the mentally handicapped [8]. However, there are still limitations in the development strategy of special education curriculum. For example, curriculum structure, service targets, service segments, local characteristics, and integration of general and special courses need to be further improved [8]. Nowadays, universal, inclusive and lifelong education has become a sustainable development trend of education, it is urgent to build the curriculum system of lifelong inclusive education. Based on this, we take Changning district as an example to explain the construction and implementation of the lifelong inclusive education curriculum system, so as to enrich the practical research of special education curriculum and provide some references for the future reform of special education curriculum.

\section{Construction of Regional Curriculum System of Lifelong Inclusive Education}

The construction of lifelong inclusive education curriculum system is based on the platform of Changning Special Education Guidance Center. The center takes resource integration as a way, the school-age, pre-school age, and post-school age project groups as starting point, community integration as direction, community (including family, school \& center) as platform for the career development of people with special education needs. Finally, the center integrates regional resources, such as special education schools, teaching and research institutions, hospitals, rehabilitation institutions, etc., to form a life-long inclusive education curriculum characterized by menu. From two aspects of direct service and indirect service, it provides support for individuals, parents and educators. The construction of regional lifelong inclusive education curriculum system is mainly carried out from four aspects: curriculum concept, curriculum structure, curriculum objective and curriculum content.

\subsection{Curriculum Concept}

Shanghai Changning Special Education Guidance Center takes special needs courses as the main body and the core of the courses. In practice, it gradually forms four keywords of the course concept in practice: lifelong, inclusive, support and talent (abbreviated as LIST).

Lifelong: supporting children throughout their lives. Lifelong education emphasizes that "the process of education and training does not end with school, but throughout the whole life". Therefore, letting all kinds of SENs of all ages develop for life, and supporting children for a lifetime is the idea that special education practitioners should pursue.

Inclusive: bringing all children together. The inclusive education philosophy emphasizes the importance of bringing SENs together with ordinary children, maintaining and fulfilling the educational opportunities and needs of every child, and bringing all children together with equal access to educational resources and opportunities.
Support: to help children achieve their dreams. The American Society for Intellectual and Developmental Disabilities emphasizes the need to provide "right-to-left" support for people with intellectual disabilities to improve their quality of life and enhance their happiness in life, that is, we should understand the capabilities of SENs and give individualized support to help children realize their dreams.

Talent: every child is the gold. This is the view of students that Shanghai Changning Special Education Guidance Center has insisted since its establishment. The SENs have all kinds of potential. Educators should discover and tap their potential, and cultivate and care for them. The SENs can shine like gold.

\subsection{Curriculum Objectives}

The courses for SENs are the core of the curriculum system. The purpose of these courses is to integrate regional special education resources, focus on the individual's potential ability and the defect compensating, provide them with diverse personalized support services, help them get professional learning opportunities to improve their and their family's quality of life, satisfy the needs of each particular lifelong development, finally promote the inclusion of SENs in the community.

The courses for parents and teachers are set up to better meet the needs of SENs. There are a large number of SENs in China, but special education teachers are short. Only by providing teachers and parents with special education resources and professional knowledge, can they give full play to their role and better serve SENs.

For families with SENs, providing professional support can promote parents' understanding and acceptance of SENs, thereby promoting the development and progress of SENs. Therefore, the main goal of the parent-oriented courses curriculum is (1) to improve the rehabilitation training ability of parents, (2) to build a home-school co-education system with school education as the main body and family education as the basis, so as to coordinate the in-school and out-of-school education, (3) to cultivate a good parent-child relationship, (4) to improve their quality of life.

The development and implementation of various projects of the center can meet the needs of teachers' professional development and professional ability improvement within the center and the region.

\subsection{Curriculum Structure}

Based on the four core concepts, with reference to the blue ocean strategic thinking, the basic positioning of the course is defined in the process of seeking differentiation. Relying on the center's three functions-- evaluation and training, research and guidance, management and service-- we have built a four-dimensional course, namely, (1) serving people with special education needs; (2) serving the parents of exceptional children; (3) serving the special education teachers, including those in the center and those in the region; (4) serving schools, including general schools and special education schools. We 
have formed a LIST curriculum, of which the courses for people with special educational needs are the core. The courses provide services for people with special educational needs in different categories. The service age ranges from birth to old age. By meeting and promoting the professional development needs of parents, teachers and principals and promoting the growth and development of individuals with special education needs, common development of the trinity of individuals, educators and parents can be realized.

\subsection{Curriculum Content}

In order to achieve the curriculum objectives, different course contents are set for different objects. The final curriculum system (as shown in Figure 1) takes special needs courses as the main line and selects teaching contents based on the actual conditions of different objects in different age groups.

The content of curriculum has the following characteristics: (1) lifelong-- courses focus on the career development of people with special education needs and provide lifelong services to meet the changing needs with age; (2) universality-- the curriculum provides educational services for all in the region. The curriculum provides services for the rehabilitation of preschool exceptional children in the form of direct or indirect, and provides cultural literacy and vocational training services for adults with disabilities. To build a lifelong education system for the disabled is to complete the basic work of building an education system of lifelong learning for all; (3) inclusiveness-- the curriculum provides services for four types of objects. In addition to exceptional children, there are also parents of children with special education needs and relevant educators (teachers and principals), which shows the inclusiveness of the curriculum. We will work together to create an inclusive environment; (4) flexibility-- the curriculum content is not immutable, but flexible. It centers on the needs of service objects and changes with the changes of demands and resources; (5) optionality-- the curriculum is presented in the form of a list, and service objects can choose courses according to their own needs.

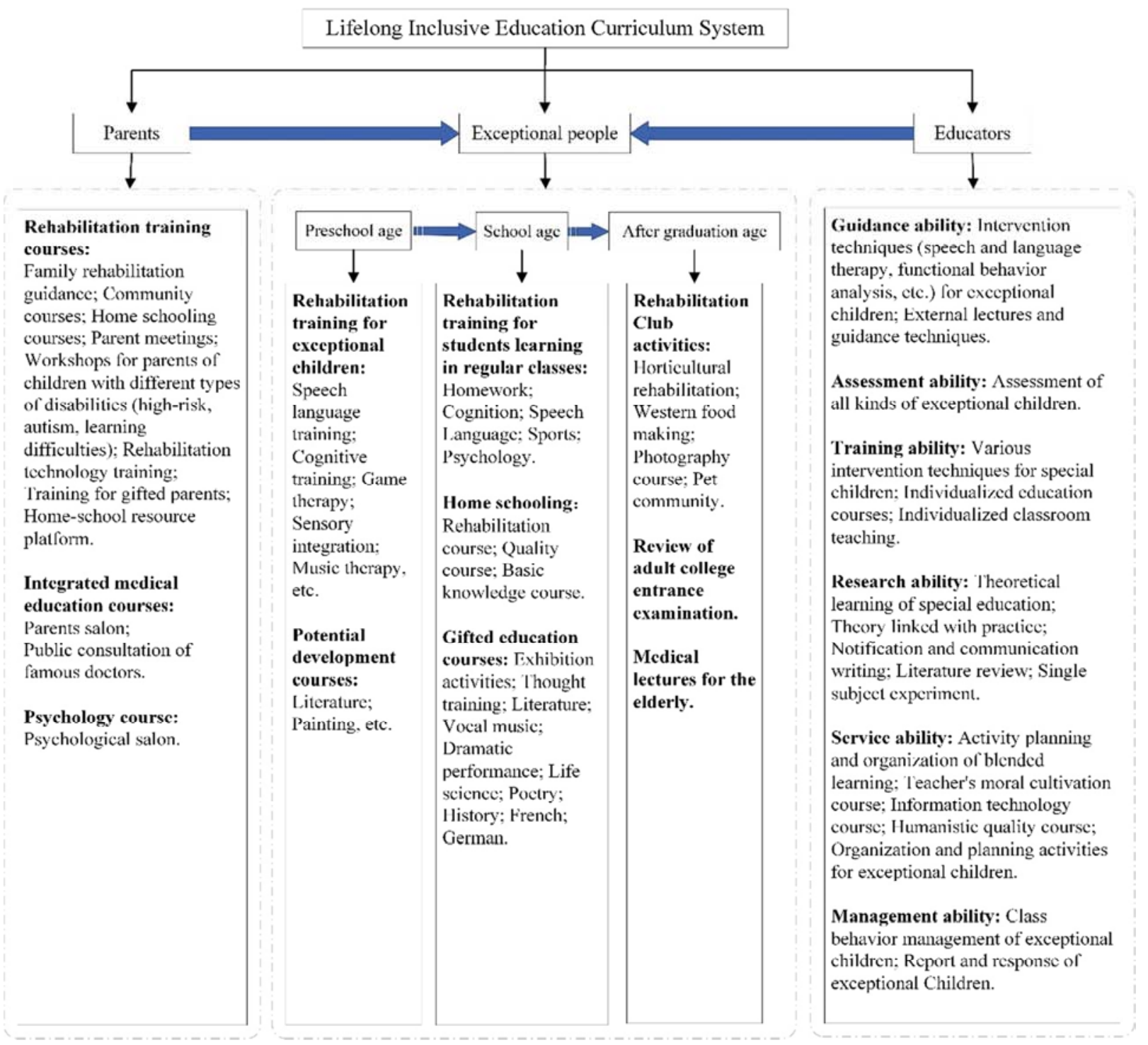

Figure 1. System structure of lifelong inclusive education curriculum. 


\section{Implementation of Regional Lifelong Inclusive Education Curriculum}

\subsection{Key Points of Curriculum Implementation}

\subsubsection{Fully Integrate Resources}

To meet the needs of different service objects, it is far from enough to only rely on the teachers in the center, which needs to make full use of the special education resources in the region. Based on the needs of service objects, the center links professional resources in the region, such as college teachers, doctors, rehabilitation teachers, special school teachers, general school teachers, and volunteer organizations. According to the needs of course contents, the center integrates different resources to form a professional service team.

\subsubsection{Rely on the Internal Research Projects of the Center}

The curriculum is supported by research projects of the central, which ensure the smooth implementation of the curriculum. The implementation of the curriculum needs a lot of personnel, materials and funds. Therefore, the developed courses are all associated with research projects, which provide resource support such as funding, personnel, etc.

\subsubsection{Enrich the Form of Curriculum Organization}

The courses are organized in various forms, which vary according to the object and the content of the course. The courses for people with special education needs mostly adopt the form of community or one/many to one. Community courses are more flexible, breaking the traditional class teaching, and can take into account the needs and potential of students. One/many to one is a personalized course based on individual potential or functional defects. The courses for parents are organized in various forms, such as salon activities, workshops, consultation with famous doctors, etc. The content of courses is rich and varied, in order to meet the different needs of parents. The courses for educators are mainly carried out in the form of listening and speaking courses, seminar activities, expert lectures, etc. The courses are closely related to its own work, so as to apply what it has learned.

\subsection{Curriculum Implementation Evaluation}

The evaluation methods of different curriculum implementation are slightly different, but they are mainly developed from the two dimensions of demonstration evaluation and development evaluation.

\subsubsection{Demonstrative Evaluation}

By means of demonstrative evaluation, we can not only understand the implementation of the courses, but also let the public know more about and approach SENs. At the same time, we can create more opportunities for SENs to contact society and integrate into community. It is both a display evaluation and a means of art therapy. In addition, it is also a good opportunity for parents and educators to show themselves to the outside world and increase the social attention to special education. The main forms of evaluation include organizing performance activities, skill competitions and commendation activities, which build a display platform for service objects. In this way, we can not only develop and tap individual potential, but also encourage and promote relevant groups to contribute to the cause of special education.

\subsubsection{Developmental Evaluation}

Developmental evaluation refers to systematically collecting evaluation information and conducting analysis to carry out evaluation, which aims to promote the continuous development of the evaluated person. The center uses a variety of methods to collect and sort out the development and changes of service targets at different stages, such as IEP, student medical file construction, case training videos, and daily family training records, etc. In this way, we can evaluate the achievement of the course objectives and provide a basis for the improvement of subsequent courses.

\section{Discussion}

\subsection{The Breakthrough of Traditional Special Education Curriculum Paradigm}

Nearly three decades of inclusive education practice, China has formed a development pattern that takes special education schools as the backbone follow special classes in general schools and learning in regular class as the main body, but general education in the elementary education curriculum reform has forgot the needs of special students. Even in the field of special education curriculum reform is limited in the special education school [9]. The curriculum reform of special education schools presents the status that the three curriculum paradigms of compensatory/ developmental/ functional are independent or compatible developing [10]. A guiding ideology of contemporary international special education curriculum reform is people-oriented, emphasis on man's comprehensive development, to maximize participation and development opportunities for SENs, improve their quality of life, and realize the value of individual existence to this end. In order to realize the special education curriculum paradigm reform, a consensus for academic circles must be design course for all students, including students with special needs, provide effective learning opportunities [11]. Lifelong inclusive education curriculum system construction take lifelong, inclusive, support and talent as LIST curriculum concept, with characteristics of nationwide, full sexual, inclusive, growing, optional, mean to the SENs complete life in the future, raise their quality of life. The curriculum takes the lead in realizing the zero breakthrough in the lifelong inclusive field in China. 


\subsection{The Application of Doll's Postmodern Curriculum Theory}

Since the $60 \mathrm{~s}$ of the 20th century, a formative rather than defined in advance, uncertain but bounded post-modern course, overthrew the $3 \mathrm{R}$ theory and set off another ideological trend. William E. Doll puts forward 4R theory curriculum paradigm, which contains richness; regression; relevance and rigor of course. Lifelong inclusive education curriculum is inspired by the postmodern curriculum theory, and it extremely has the characteristics of postmodern curriculum $[12,13,14]$.

\subsubsection{The Richness and Growth of the Course Content}

Richness mainly embodied in the curriculum with uncertainty; abnormity; inefficiencies; ambiguity; imbalance; dissipation and vivid experience. Compared with solidify the curriculum teaching, needing a variety of school-based courses to enrich the course content, lifelong inclusive education curriculum system has extremely rich and growing course content, which has more obvious openness, with iterative updating.

\subsubsection{The Regression and Openness of the Curriculum Framework}

Regression aim at developing the ability to organize, combine, and inspire the use of something whose framework is open, dual, elastic, and interpretive. Lifelong inclusive education curriculum system is to advocate, support and use of regression classes. The whole course based on the UNESCO Education 2030 Framework for Action: " Ensure inclusive and equitable quality education and promote lifelong learning opportunities for all ", closely around education objective of "inclusive", "fairness", "quality" and "lifelong learning", to create a regional lifelong inclusive education system on this logical framework.

\subsubsection{The Relevance and Culture of Curriculum Structure}

Relevance refers to the link of education and culture, the former refers to the rich network connection in the course, the latter refers to extra-curricular culture and cosmology links. Lifelong inclusive education points to the future, throughout ones career, related to student's home /school and community and so on ecological system. The curriculum was delivered under the guidance of the Fourth Plenary Session of the 19th Central Committee which proposed a national lifelong learning education system. Lifelong inclusive education curriculum is accord with the actual conditions of China and full of Chinese characteristics.

\subsubsection{The Uncertainty and Multiple Interpretation of the Course "Rigor"}

Rigor comes from the uncertainty of the course and the combination of explanatory, uncertainty have specific contexts or situations. Knowledge is constantly changing, under the premise of rigor in uncertainty, use multiple interpretations to improve, must continuously explore and seek new combination interpretation or model. Lifelong inclusive education is a growing course system, it fully integrated local education resources, such as regional special-education schools; general schools; universities; research institutions; hospital; rehabilitation institutions; volunteer teams to provide services. After years of practice, Changning has formed a LIST curriculum menu, which is still under constant innovation and reform.

\subsection{Innovation of Regional Lifelong Inclusive Education Curriculum System}

\subsubsection{Enlargement of Learning Segment}

Current domestic special education curriculum reform focused on special education schools, namely the compulsory education period. In recent years, China Second Phase of Special Education Enhance Program (2017-2020) was published, putting forward that special education should be benefit to both ends--preschool and vocational education. Some areas start to initiate preschool and vocational special education services, but from the overall situation, haven't have from the perspective of the SENs lifelong inclusive education development courses. The construction of the curriculum system of lifelong inclusive education in changning district extends from preschool learning to career development. The curriculum covers people with special education needs from 0-3 years old to the elderly, realizing the lifelong extension of the curriculum period of inclusive education.

\subsubsection{Extension of Handicap Types}

Individuals with Disabilities Education Act of 2004 (IDEA) stipulates that there are 13 types of special education service objects in the United States. The special education law promulgated in Taiwan, China on 2014 stipulates that there are 19 types of special education service groups, including 13 types of physical or mental disorders and 6 types of gifted or talented. Special education in China mainland has not yet issued a complete legal system, only from the 2011 national standard disability classification and grading, dividing disabled people into 7 types: mental; vision; hearing; speech; physical and multiple disabilities. Existing special education school curriculum standards only involve services for blind, deaf and mentally retarded, haven't cover special education services for ADHD; learning disabilities; emotional and behavior disorders; speech and language disorders; developmental retardation and gifted students in the general school. The lifelong inclusive education curriculum system in changning district conforms to international trend, and has constructed the curriculum construction from supporting disabled students to supporting the SENs, so as to more accurately and effectively support a wider range of groups with special educational needs.

\subsubsection{Expansion of Service Object}

American scholar Mr Bronfenbrenner (Urie Bronfenbrenner) has proposed bioecological theory. It emphasize to put one's development into the ecosystem, and children have a direct or indirect relationship between the ecological environment, such as family, school and community, all of them affecting the overall development of 
children. Ecological environment is an interaction system, the more environment factors help, the better child develop. So we need to focus on the influence factors of individual and its ecological system closely linked [15]. Changning district lifelong inclusive education curriculum system not only developed a lot of direct services for service-oriented SENs, but also more indirect services for the their parents, teachers and headmaster. From the Angle of individual ecological support, Changning has finished course construction to support parents, teachers and headmaster.

\section{Conclusion}

\subsection{A "LIST" of Lifelong Inclusive Education Curriculum System Has Been Formed}

The curriculum is supported by the center project and forms a LIST of courses. The overall course system will be adjusted annually according to the implementation of the previous year and the change of resources. The project has undergone four adjustments from 2016 to 2019.

Table 1. Four versions support item LIST item comparison.

\begin{tabular}{|c|c|c|c|c|c|}
\hline Listing version & Support campus President & Support teachers & Support parents & Support students & Item counts \\
\hline 2016 version & 3 & 12 & 10 & 7 & 32 \\
\hline 2017 version & 4 & 15 & 14 & 13 & 46 \\
\hline 2018 version & 6 & 16 & 15 & 17 & 54 \\
\hline 2019 version & 6 & 19 & 13 & 15 & 53 \\
\hline
\end{tabular}

\subsection{Changed the Whole Face of Regional Special Education}

Lifelong inclusive education curriculum construction has realized the expansion of service object, not only service students in our center, but also autism spectrum disorders, learning disabilities (include ADHD; dyslexia; dysgraphia; dyscalculia), emotional and behavior disorders, speech and language disorders, gifted students, health impairments students and etc special education needs students in general schools. The curriculum take basic education as priority, extending service length--stretch forward of preschool education and post-school education--servicing from 0-3 years old to adulthood and the old age. New type of service object are include, not only disable students, but also the regional SENs. From two aspects of direct service and indirect service, to provide support for SENs. The Curriculum take lifelong inclusive education and international education philosophy as the theoretical basis, trying to build a special education needs lifelong education curriculum system. inclusive education object provides lifelong career support services, optimize the work of the national education, change the face of the area of special education.

\subsection{A sample of Regional Curriculum System of Lifelong Inclusive Education is Provided}

Based on regional inclusive system construction and practice, changning district, focusing on the inclusive education compulsory education stage, both ends to extension education, developing in each period transition services, constructing from preschool inclusive education to the SENs lifelong inclusive education curriculum system. It realize the regional special education longitudinal and transverse to the edge of the public services [16]. The curriculum is explored and formed with Chinese characteristics, covering disable, disability and gifted students of special education service, and gradually promote the implementation of lifelong inclusive education curriculum system.

\section{Acknowledgements}

This is the phased research result of the key project of Ministry of Education of the People's Republic of China for the 13th Five-Year Plan of National Education Science in 2016 Deepening Research on the Construction of New Special Education Schools in Respond to Inclusive Education. (subject approval Number: DHA160368). Project leader is Feng Xia. We thank Yuzhen Xu, Meixian Huang, Lijiang, Can Liu, Yongfen Gu, Lian Lu, Zhen Tang, Shen'e Huang, Yao Wang, Shuqiong Yan, Aihua Dai, Caihong Hu, Yi Chen, Yan Wang for their efforts in this study.

\section{References}

[1] Xu, L., Wang, M., \& Cheng, H. D. (2015). New Journey of Global Education to Lifelong Learning: Interpret the Goal and Targets Section of Education 2030 Framework for Action. Open Education Research, 118 (06), 18-27.

[2] The People's Daily (2019, December, 4); The fourth plenary session of the 19th CPC central committee was held in Beijing.

[3] Lei, J. H., Fang, J. M. (2011). Special education. Beijing: Peking University Press.

[4] Li, L. (2015). An Investigation on the Construction of Special Teacher Education System in China (Doctoral dissertation). Retrieved from http://dwz.date/bgA4.

[5] Huang, J. H. (2015). The Pursuit of Fairness and Excellence: Research on the Development and Reformation of Special Education in the United States (Doctoral dissertation). Retrieved from http://dwz.date/bgAT.

[6] Ministry of Education of the People's Republic of China. (2016). Notice of the Ministry of Education on the implementation of the "Compulsory Education Curriculum Standards for Blind Schools (2016 Edition)", "Compulsory Education Curriculum Standards for Deaf Schools (2016 Edition)" and "Compulsory Education Curriculum Standards for Schools with Intellectual Disabilities (2016 Edition)". $\quad$ Retrieved from http://www.moe.gov.cn/srcsite/A06/s3331/201612/t20161213_ 291722.html. 
[7] Zhong, J. F. (2016). The Ministry of Education promulgates the implementation of compulsory education curriculum standards for three types of special education schools: blindness, deafness and intellectual disabilities. Retrieved from http://www.moe.gov.cn/jyb xwfb/gzdt gzdt/s5987/201612/t2 0161213_291720.html.

[8] Li, S. W. (2019). The Developmental Strategies of Special Education Curriculum in China: Retrospection and Prospect. Modern Special Education, 12, 3-11.

[9] Sheng, Y. J. (2013). The Development of International Special Education Curriculum Based on the Value of Inclusion. Studies in Foreign Education, 9, 90-97.

[10] Sheng, Y. J. (2012). The Transformation of Contemporary Special Education Curriculum Paradigms. Studies in Foreign Education, 1, 100-107.

[11] Sheng, Y. J. (2011). The Relationship between Adaptive Believes, Coping Style and Mental Health among Candidate teachers. Chinese Journal of Special Education, 12, 23-27, 83.
[12] Doll, W. E., Wang, Y. H. (2015). Post-modern perspective on curriculum Chinese. Beijing: Educational Science Publishing House.

[13] Yue, G. D. (2007). On the Richness of Curriculum: Study of Postmodern Curriculum Thought of William E. Doll, Jr.. Global Education, 35 (4), 27-32.

[14] Rong, ZH. K. (2007). The Modern Points of View of Curriculum vs the Position of Practice of Our Curriculum. Elemental and Secondary Education in Foreign Countries, 7, $15-17$.

[15] Su, X. Y.(2016). Early intervention in infants and young children. Shanghai: East China Normal University Press.

[16] Xia, F. \& Xu, Y. ZH. (2016). On the Service System for Regional Lifelong Special Education Based on Lifelong Learning for All - Practice from Changning District, Shangha. Chinese Journal of Special Education, 10, 3-8. 